\title{
THE INFLUENCE OF PLASMONIC AU NANOPARTICLE INTEGRATION ON THE OPTICAL BANDGAP OF ANATASE TiO2 NANOPARTICLES
}

\author{
Munawar Khali1 ${ }^{*}$, Gita Rahmaningsih ${ }^{1}$, Jarnuzi Gunlazuardi ${ }^{1}$, \\ Aminar Umar ${ }^{1}$ \\ ${ }^{1}$ Department of Chemistry, Faculty of Mathematics and Natural Sciences, Universitas Indonesia, \\ Kampus UI Depok, Depok 16424, Indonesia.
}

(Received: November 2018 / Revised: December 2018 / Accepted: March 2019)

\begin{abstract}
This work reports an investigation into the influence of the surface plasmon resonance (SPR) phenomenon of plasmonic Au nanoparticles on the optical bandgap of anatase titanium dioxide $\left(\mathrm{TiO}_{2}\right)$ nanoparticles. In the study, the effect of particle integration on the optical bandgap of $\mathrm{TiO}_{2}$ nanoparticles was studied in two types of binary $\mathrm{Au}-\mathrm{TiO}_{2}$ heterostructured materials, namely Janus $\mathrm{Au}-\mathrm{TiO}_{2}$ nanostructures and core-shell $\mathrm{Au} @ \mathrm{TiO}_{2}$, and their optical absorption spectra were compared to the pristine anatase $\mathrm{TiO}_{2}$ nanoparticles. The anatase $\mathrm{TiO}_{2}$ nanoparticles was prepared using the sol-gel method. Well-dispersed Au nanoparticles with particle size diameter in the range of 19-33 nm were successfully synthesized using the seed-mediated method and exhibited unique light absorption due to SPR at $544 \mathrm{~nm}$. Based on the results, the integration of Au nanoparticles was found to be responsible for the alteration of both light absorption behavior and the optical bandgap of $\mathrm{TiO}_{2}$. Spectroscopic analyses revealed that the presence of the SPR phenomenon was able to widen the light absorption range of $\mathrm{TiO}_{2}$ to the visible spectrum. In addition, the optical bandgap of the heterostructures was found to be slightly lower than the corresponding pristine anatase $\mathrm{TiO}_{2}$ nanoparticles.
\end{abstract}

Keywords: Au nanoparticles; Bandgap; Kubelka-Munk; Plasmonic; $\mathrm{TiO}_{2}$ nanoparticles

\section{INTRODUCTION}

Recent advances in the development of nanostructured materials, with precise control in size and shape, have enabled researchers to unlock various new optical, electronic and magnetic properties (Duan et al., 2015; Ahmed et al., 2016). Tremendous efforts have also been made to utilize such technology in the fabrication of new types of material with exceptional physicochemical properties, which can be used in various applications such as electronics, catalysis, oil and gas, biomedical and energy storage/conversion (Sharma et al., 2015; Khalil et al., 2017). Exceptional new functionalities can also be obtained by the formation of hybrid nanostructures, in which two or more nanostructured materials are combined. For instance, enhancement in the optical, electronic and photocatalytic properties of various dielectric oxide and semiconductors can be achieved by integrating them with plasmonic metal nanoparticles to form metal-oxide hybrid nanostructured materials (Hernández-Ramirez et al., 2017).

Over the past decades, nano-sized titanium dioxide $\left(\mathrm{TiO}_{2}\right)$ has been widely considered as one of the most photoactive materials for catalysis in various photocatalytic reactions, due to its chemical stability, low toxicity and corrosion resistance (Low et al., 2017). Studies have shown

*Corresponding author's email: mkhalil@sci.ui.ac.id, Tel. +62-21-7270027, Fax. +62-21-7863432

Permalink/DOI: https://dx.doi.org/10.14716/ijtech.v10i4.2605 
that multiple forms of $\mathrm{TiO}_{2}$ nanostructures have been extensively used as photocatalytic material in photo-induced solar fuel generation, such as $\mathrm{CO}_{2}$ reduction and water splitting, photo oxidation of pollutants in wastewater remediation, and photovoltaic devices (Ayati et al., 2014; Clavero, 2014; Tahir \& Amin, 2015; Sofyan et al., 2017). Unfortunately, the large $\mathrm{TiO}_{2}$ bandgap $(\sim 3.2$ $\mathrm{eV})$ often limits its application in the development of solar-driven photocatalytic reactions, as it only absorbs in the ultraviolet (UV) region (Dette et al., 2014). Furthermore, the rapid recombination of the photo generated charge carriers, i.e. "the excited hot electrons" and "holes", may also diminish the photocatalytic efficiency of $\mathrm{TiO}_{2}$ (Tan et al., 2011).

It has recently been suggested that hetero structuring of $\mathrm{TiO}_{2}$ with plasmonic particles such as $\mathrm{Au}$ or Ag nanoparticles could be used to solve these two aforementioned major issues, and thus enhance the photocatalytic performance of $\mathrm{TiO}_{2}$ (Ran et al., 2018). Generally, the role of plasmonic particles in this hetero structured system is very similar to organic dyes or transition metal complexes, which act as photosensitizers. It is believed that hot electrons generated during the Localized Surface Plasmon Resonance (LSPR) process, which typically occur when plasmonic particles are irradiated using visible light, could be transferred to the $\mathrm{TiO}_{2}$ conduction band, which could further be used to facilitate redox reactions (Hidalgo et al., 2009; Lin et al., 2015). As a result, the photocatalytic activity of $\mathrm{TiO}_{2}$ could be extended to a broader light spectrum, e.g. the visible region, which allows the utilization of such materials for solar-driven photocatalytic processes such as artificial photosynthesis.

Currently, a great deal of effort is being made to fully understand the role of plasmonic particles in the enhancement of the photocatalytic activity of $\mathrm{TiO}_{2}$. However, an only a small fraction of the current interest is being paid to the effect of plasmonic particle integration on the electronic structure of $\mathrm{TiO}_{2}$. Therefore, an investigation into the role of plasmonic Au nanoparticles on the bandgap tuning of anatase $\mathrm{TiO}_{2}$ nanoparticles is presented in this study. In the study, welldistributed $\mathrm{Au}$ and anatase $\mathrm{TiO}_{2}$ nanoparticles were fabricated using the seed-mediated and solgel methods respectively. In addition, two types of binary $\mathrm{Au}-\mathrm{TiO}_{2}$ heterostructured materials, namely Janus $\mathrm{Au}-\mathrm{TiO}_{2}$ nanostructures and core-shell $\mathrm{Au} @ \mathrm{TiO}_{2}$ nanostructure, were also synthesized to investigate the effect of the plasmonic phenomenon on the optical bandgap of semiconductors.

\section{EXPERIMENTAL METHODS}

\subsection{Materials}

Titanium(IV) isopropoxide (TTIP) (purity: 97\%), $\mathrm{NH}_{4} \mathrm{OH}$ solution (28-30\% $\mathrm{NH}_{3}$ in $\mathrm{H}_{2} \mathrm{O}$ ) and absolute ethanol were purchased from Sigma-Aldrich and used in the sol-gel reaction for the synthesis of the anatase $\mathrm{TiO}_{2}$ nanoparticles. Gold(III) chloride hydrate $\left(\mathrm{HAuCl}_{4} \cdot \mathrm{xH}_{2} \mathrm{O}\right.$ ) (purity: 99.5\%) was also obtained from Sigma-Aldrich and used as the precursor for the synthesis of the $\mathrm{Au}$ nanoparticles. Furthermore, hydroxylamine hydrochloride $\left(\mathrm{NH}_{2} \mathrm{OH} \cdot \mathrm{HCl}\right)$ (purity: 99.99\%) and Na-citrate (purchased from Sigma-Aldrich) were also used in the synthesis of the Au nanoparticles. In addition, hydrochloric acid $(\mathrm{HCl})$ obtained from Sigma-Aldrich was used in the synthesis of the Janus $\mathrm{Au}-\mathrm{TiO}_{2}$ nanostructure. In this work, all the chemicals were used without further purification.

\subsection{Synthesis of $\mathrm{TiO}_{2}$ Nanoparticles}

The process of $\mathrm{TiO}_{2}$ nanoparticle synthesis was conducted using a slight modification technique to a method reported in previous work, in which TTIP was used as the titanium precursor (Li et al., 2012). In this case, $0.75 \mathrm{~mL}$ of TTIP was mixed vigorously at $45^{\circ} \mathrm{C}$ for 6 hours with a solution containing $0.3 \mathrm{~mL}$ of $\mathrm{NH}_{4} \mathrm{OH}$ and $100 \mathrm{~mL}$ of absolute ethanol. The mixture was then centrifuged at $6000 \mathrm{rpm}$, and the white precipitate was collected and washed three times with ethanol. The obtained white powder was then dried overnight in an oven at $60^{\circ} \mathrm{C}$ before being calcinated at 
$450^{\circ} \mathrm{C}$ for 2 hours for further investigation.

\subsection{Synthesis of Plasmonic Au Nanoparticles}

In this work, a seed-mediated method was used to prepare the plasmonic Au nanoparticles (Haiss et al., 2007). Au seed particles were made by mixing $125 \mathrm{~mL}$ of $0.254 \mathrm{mM} \mathrm{HAuCl}_{4} \cdot \mathrm{xH}_{2} \mathrm{O}$ and $12.5 \mathrm{~mL}$ of $40 \mathrm{mM}$ Na-citrate vigorously until the color of the solution became deep red. The mixture was then boiled for 15 minutes before being cooled to room temperature to obtain the final $\mathrm{Au}$ seed particle solution. Furthermore, to synthesize Au nanoparticles with a bigger particle size, $20 \mathrm{~mL}$ of Au seed particle solution was diluted in $180 \mathrm{~mL}$ of deionized water which would then be mixed with $7 \mathrm{~mL}$ of $2 \mathrm{M} \mathrm{NH} \mathrm{H}_{2} \mathrm{OH} \cdot \mathrm{HCl}$ and $3 \mathrm{~mL}$ of $10 \mathrm{mM}$ of $\mathrm{HAuCl}_{4} \cdot \mathrm{xH}_{2} \mathrm{O}$. The resulting colloidal solution was then stored at $4^{\circ} \mathrm{C}$ in darkness and used for further investigations.

\subsection{Synthesis of Janus Au-TiO2 Nanostructures}

The Janus $\mathrm{Au}-\mathrm{TiO}_{2}$ nanostructures were prepared by integrating the previously prepared $\mathrm{Au}$ and $\mathrm{TiO}_{2}$ nanoparticles in acidic condition, following a study reported by Zhang et al. (2016). Typically, 0.1 grams of $\mathrm{TiO}_{2}$ nanoparticles were mixed with $50 \mathrm{ml}$ of colloidal Au nanoparticle solution. The $\mathrm{pH}$ of the mixture was then adjusted to $\mathrm{pH} 3$ by slowly adding $0.01 \mathrm{M}$ of $\mathrm{HCl}$ solution while stirring vigorously for 30 minutes at room temperature. The mixture was then centrifuged, and the precipitate obtained was collected and washed with deionized water and ethanol respectively. The precipitate was then dried in a vacuum oven at $60^{\circ} \mathrm{C}$ overnight, and the resulting powder was collected for further characterization.

\subsection{Synthesis of Core-Shell Au@ $\mathrm{TiO}_{2}$ Nanostructures}

The method for the synthesis of the core-shell $\mathrm{Au} @ \mathrm{TiO}_{2}$ nanostructures was adopted from Li et al. (2012), with slight modification. In this work, core-shell structures were prepared by a kinetically controlled coating method. Typically, the as-prepared colloidal Au nanoparticles were dispersed in $100 \mathrm{~mL}$ ethanol absolute and mixed with $0.3 \mathrm{~mL}$ of $\mathrm{NH}_{4} \mathrm{OH}$ solution with vigorous mixing for 15 minutes. Furthermore, $0.75 \mathrm{~mL}$ TTIP was added dropwise to the mixture and the reaction was further allowed to proceed for another 24 hours at $45^{\circ} \mathrm{C}$ with continuous mixing. The final solution was then centrifuged, and the precipitate was collected and then washed with deionized water and ethanol respectively. Finally, the obtained powder was dried in a vacuum oven for 24 hours at $60^{\circ} \mathrm{C}$ and further calcinated at $450^{\circ} \mathrm{C}$ for 2 hours. The final powder was then used for further investigations.

\subsection{Characterization}

To investigate both the physical and chemical properties of the as-prepared nanostructures, various characterization methods were conducted. To study the crystal structure of the nanomaterials, X-Ray Diffraction (XRD) analysis was carried out using PANanalytical X'Pert Pro MPD (PANanalytical B.V., Almelo, the Netherlands), equipped with an X'Celerator detector with $\mathrm{Cu}-\mathrm{K} \alpha$ radiation as the source. The formation of $\mathrm{TiO}_{2}$ nanoparticles during the sol-gel reaction was also studied by FTIR analysis using Shimadzu IR Prestige 21. The nanoparticle size, shape and morphology were determined by collecting the micrographic image of the nanoparticles using TECNAI G2 Spirit Twin High-Resolution Transmission Electron Microscope (HR-TEM). Furthermore, both the electronic and spectroscopic properties of the nanoparticles were studied using Shimadzu UV-2450.

\subsection{Optical Bandgap Measurement}

In this study, the optical bandgap $\left(E_{\mathrm{g}}\right)$ of the as-prepared nanoparticles was determined using the Kubelka-Munk method (Singaravelan \& Alwar, 2015). The optical bandgap energy was calculated according to the Tauc equation (Tauc, 1968), which can be expressed as follows:

$$
(\alpha h v)^{n}=A\left(h v-E_{\mathrm{g}}\right)
$$


where $h$ is the Planck's constant $\left(6.626 \times 10^{-34} \mathrm{~J} . \mathrm{s}\right), v$ is the light frequency, $A$ is the proportional constant, $E_{\mathrm{g}}$ represents the optical bandgap $(\mathrm{eV})$, the $n$ value is $1 / 2$ for the allowed direct transition, and $\alpha$ expresses the absorption coefficient, which can be determined from the diffuse reflectance spectrum using the Kubelka-Munk equation according to the following equation:

$$
\mathrm{F}(R)=\frac{(1-R)^{2}}{2 R}=\frac{k}{s}
$$

where $\mathrm{F}(R)$ is the Kubelka-Munk function acquired from the diffuse reflectance spectrum and is equivalent to the absorption coefficient $(\alpha), R$ represents the absolute reflectance of the nanoparticles, $k$ is the molar absorption coefficient, while $s$ is the scattering coefficient. By integrating Equations 1 and 2, the optical bandgap of the as-prepared nanoparticles can be estimated by plotting the quantity of $[\mathrm{F}(R) h v]^{1 / 2}$ against the photon energy $(h v)$, from which the bandgap value is obtained as the intercept of the fitted straight line from the linear part of the curve.

\section{RESULTS AND DISCUSSION}

\subsection{Fabrication of $\mathrm{TiO}_{2}$ Nanoparticles}

In the literature, various methods have been widely investigated for the synthesis of $\mathrm{TiO}_{2}$ nanoparticles. However, the sol-gel method is one of the most commonly used techniques, since it offers very easy control of the size and morphology of the resulting particles. In this work, this method was used to fabricate the desired $\mathrm{TiO}_{2}$ nanoparticles, with TTIP used as the titanium source. Furthermore, to investigate the formation of the photocatalytically-active nanosized $\mathrm{TiO}_{2}$ crystal, the products obtained before and after calcination were characterized using FTIR and XRD. Figure 1 presents the FTIR spectra and XRD pattern of the reaction products obtained from the sol-gel reaction.
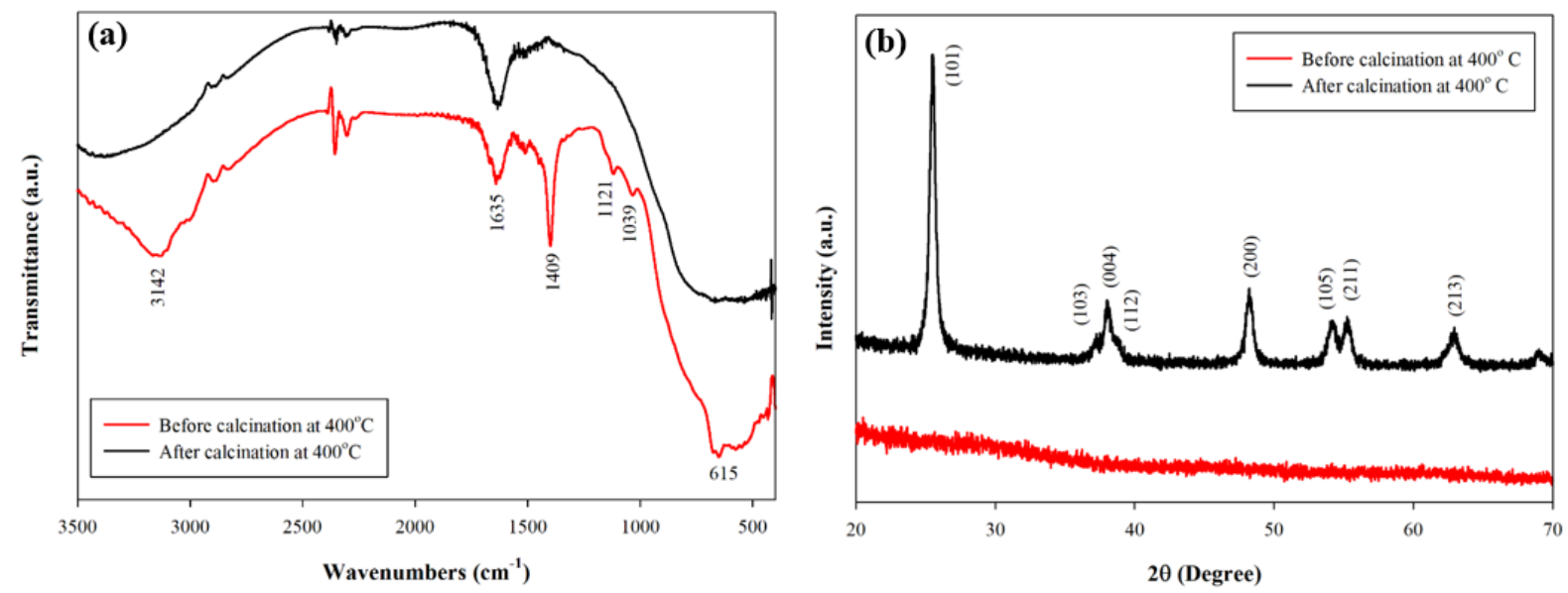

Figure 1 (a) FTIR spectra and (b) XRD patterns of sol-gel reaction products before and after calcination at $400^{\circ} \mathrm{C}$

Based on the FTIR analysis, it can be observed that the reaction products obtained before and after calcination show some similar absorption peaks (Figure 1a). For instance, both IR spectra exhibit a vibration mode for O-H stretching at around 3000-3400 $\mathrm{cm}^{-1}$. A sharp peak can also be observed at $1635 \mathrm{~cm}^{-1}$ due to absorption of the H-O-H bending vibration (Devi et al., 2009). Furthermore, both spectra also show an intense band around 500-900 $\mathrm{cm}^{-1}$, which can be attributed to the bending vibration of Ti-O-Ti due to the formation of the skeleton structure of anatase $\mathrm{TiO}_{2}$. However, there is a strong absorption at $3142 \mathrm{~cm}^{-1}$ in the reaction product before calcination, which may be caused by the absorption of $\mathrm{C}-\mathrm{H}$ stretch due to the presence of unreacted TTIP. This is also proved by the appearance of strong peaks at 1409, 1121 and 1039 
$\mathrm{cm}^{-1}$ due to the absorption of various vibration modes from excess reactants. However, these peaks disappeared when the reaction product was calcinated because of the formation of denser inorganic phase of anatase $\mathrm{TiO}_{2}$. The crystal phase transformation is also supported by XRD analysis (Figure 1b). Based on the results, the XRD pattern of the reaction product after calcination can be unambiguously ascribed as the anatase crystal phase. Meanwhile, the reaction product before calcination was rather amorphous. Micrographic image analysis with TEM also revealed that the as-synthesized nanoparticles had a spherical morphology, with an average particle size diameter of around 200-300 nm (Figure 2a). Besides, further fast Fourier transform (FFT) analysis of the HR-TEM image also provides additional evidence for the formation of the anatase crystal phase (Figure 2b).
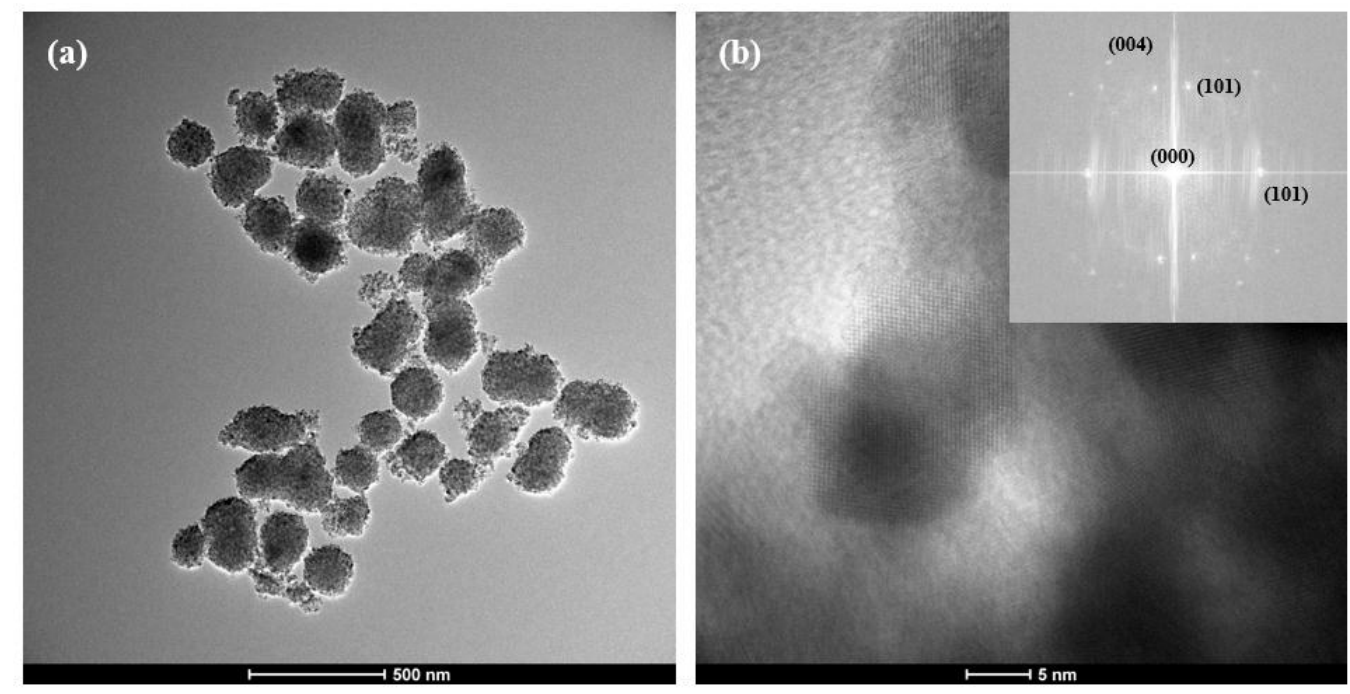

Figure 2 (a) TEM image and (b) HR-TEM image of the sol-gel reaction product after calcination (inset: the corresponding FFT pattern).

\subsection{Fabrication of Au Nanoparticles}

In this work, the fabrication of plasmonic Au nanoparticles was performed by a seed-mediated method. This method is generally preferred, since it allows full control of the morphology, size, and dispersity of the as-prepared $\mathrm{Au}$ nanoparticles. In this case, small Au seed crystal seed particles were initially synthesized, with sodium citrate used as both the strong reducing agent and stabilizer. The seeds were grown further into bigger and more stable Au particles using $\mathrm{NH}_{2} \mathrm{OH} \bullet \mathrm{HCl}$ as a milder reducing agent. Figure 3a shows the micrographic image of the reaction product obtained from the synthesis of Au nanoparticles using the seed-mediated method. Based on the results, it can be observed that the seed-mediated crystal growth method was able to form nano-sized Au particles with spherical morphology. Figure $3 \mathrm{a}$ also reveals that the as-prepared Au nanoparticles have good dispersity, with particle diameter in the range of $19-33 \mathrm{~nm}$. The formation of these particles is believed to follow LaMer's nucleation theory, in which the growth mechanism can be divided into three stages: (i) production of metal atoms; (ii) nucleation of seed particles; and (iii) nanoparticle growth by the addition of metal atoms to the seed particles (Polte et al., 2010). Furthermore, the formation of nano-sized Au particles was also confirmed by UVVis spectroscopy, in which the Surface Plasmon Resonance wavelength $\left(\lambda_{\text {SPR }}\right)$ was found at 544 $\mathrm{nm}$ (Figure 3b). 

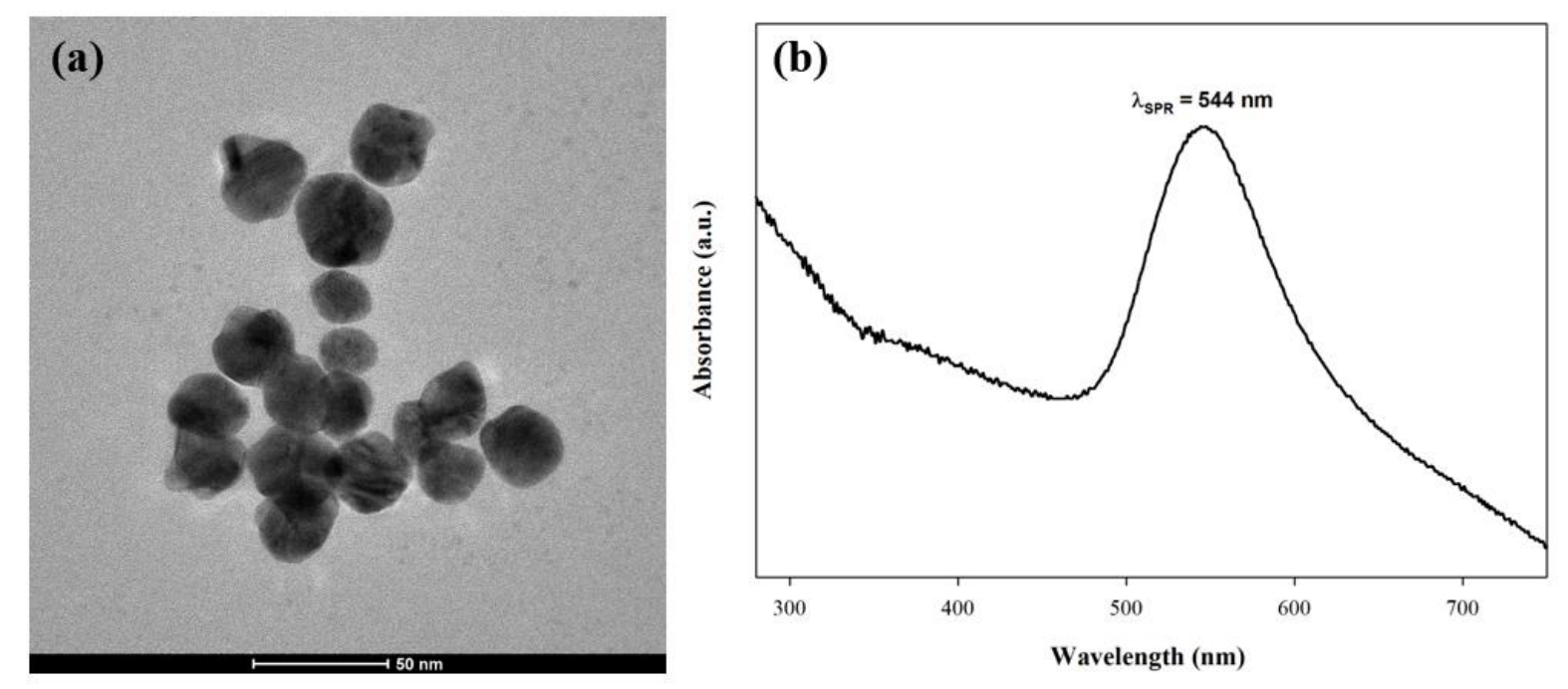

Figure 3 (a) TEM image and (b) UV-Vis spectrum of the as-prepared Au nanoparticles

\subsection{Integration of $\mathrm{TiO}_{2}$ and Au Nanoparticles}

To study the integration effect of plasmonic Au nanoparticles on the optical bandgap of anatase $\mathrm{TiO}_{2}$ nanoparticles, two binary heterostructures of $\mathrm{Au}$ and $\mathrm{TiO}_{2}$ nanoparticles were prepared. Figure 4 presents the TEM images of the reaction products obtained from the integration reaction of $\mathrm{Au}$ and $\mathrm{TiO}_{2}$ nanoparticles. Based on the results, it can be observed that it was possible to integrate the plasmonic Au nanoparticles into the $\mathrm{TiO}_{2}$ nanoparticles with two different types of integration mode. In the first mode, the $\mathrm{Au}$ nanoparticles were attached to the surface of the anatase $\mathrm{TiO}_{2}$ nanoparticles, creating a so-called Janus Au-TiO 2 nanostructure (Figures 4a-4b). In this way, several small Au nanoparticles could easily be attached to the surface of the $\mathrm{TiO}_{2}$ nanoparticles by simply adjusting the $\mathrm{pH}$ of the colloidal solution containing a mixture of $\mathrm{Au}$ and $\mathrm{TiO}_{2}$ nanoparticles. The results also show that the integration of both types of particle did not alter the size and morphology of the nanoparticles. Furthermore, Au nanoparticles could also be easily distinguished from $\mathrm{TiO}_{2}$ nanoparticles by conducting FFT analysis of the HR-TEM images of the Janus $\mathrm{Au}-\mathrm{TiO}_{2}$ nanostructures (Figure 4b). Based on Figure 4c, the darker area of the image can be identified as Au nanoparticles since the FFT patterns show both (111) and (101) planes, which is in close agreement with the Au FCC crystal $d$-spacing at 0.235 and $0.281 \mathrm{~nm}$ respectively (Singh et al., 2016). In addition, FFT analysis of the brighter area of the nanostructures shows both (101) and (004) planes of anatase $\mathrm{TiO}_{2}$, which can be indexed as crystal $d$-spacing at 0.352 and $0.238 \mathrm{~nm}$ respectively (Figure 4d) (Medina-Ramírez et al., 2014).

For the second type of integration mode, $\mathrm{TiO}_{2}$ nanoparticles were grown on top of the $\mathrm{Au}$ nanoparticles to create a core-shell $\mathrm{Au} @ \mathrm{TiO}_{2}$ nanostructure. The formation of this nanostructure was confirmed by the micrographic image of the reaction product obtained from the integration reaction (Figure 4e). In addition, core $\mathrm{Au}$ nanoparticles can easily be distinguished from shell $\mathrm{TiO}_{2}$ by carrying out FFT analysis of the HR-TEM image of the core-shell Au nanostructure (Figure 4f). Based on the results, FFT analysis of the darker core particles show a (111) crystal plane, which can be ascribed as $d$-spacing of Au FCC at $0.235 \mathrm{~nm}$ (Figure 4g). In addition, FFT analysis of the brighter shell particles shows $d$-spacing values at 0.243 and $0.352 \mathrm{~nm}$, which correspond to (103) and (101) planes of anatase $\mathrm{TiO}_{2}$ crystal (Figure 4h). 

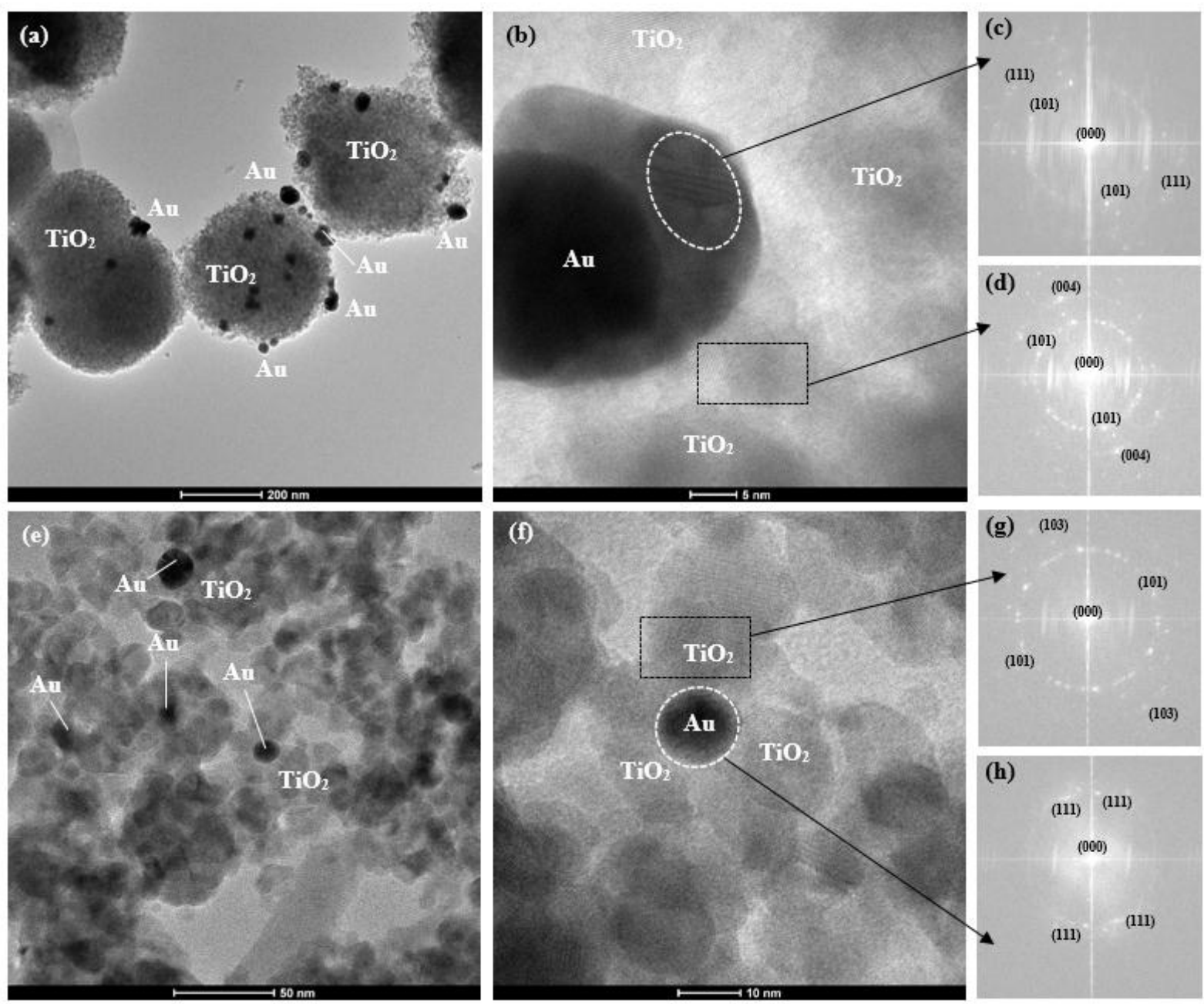

Figure 4 (a) TEM and (b) HR-TEM images of the Janus $\mathrm{Au}-\mathrm{TiO}_{2}$ nanostructure; (c)-(d) the corresponding FFT patterns for $\mathrm{Au}$ and $\mathrm{TiO}_{2}$ respectively; (e) TEM and (f) HR-TEM images of the coreshell $\mathrm{Au} @ \mathrm{TiO}_{2} ;(\mathrm{g})-(\mathrm{h})$ the corresponding FFT for $\mathrm{TiO}_{2}$ and Au respectively

\subsection{Effect of $\mathrm{Au}-\mathrm{TiO}_{2}$ Integration on Bandgap}

Measurement of optical bandgap has been considered one of the key factors in determining the potential applicability of a particular semiconducting material such as $\mathrm{TiO}_{2}$ in various types of applications, including photocatalysis. Typically, highly crystalline anatase $\mathrm{TiO}_{2}$ nanoparticles would have a bandgap value in the range of 3.2 (Singaravelan \& Alwar, 2015). Nevertheless, recent studies have also reported that several factors, such as the crystallinity, presence of impurities, crystal defects, nanoparticle grain size, and oxygen deficiencies could often alter the bandgap value of a typical semiconducting material such as $\mathrm{TiO}_{2}$ (Hidalgo et al., 2007). Moreover, doping of metal or metal ions, as well as integration with other types of photoactive material such as other semiconductors and plasmonic particles, could change the bandgap of $\mathrm{TiO}_{2}$ (Chen \& Burda, 2008). In this work, the effect of plasmonic Au nanoparticles on the optical bandgap of $\mathrm{TiO}_{2}$ nanoparticles with different integration modes was evaluated from the UV-Vis DRS analyses. Figure 5 shows the UV-Vis DRS spectra and the Kubelka-Munk plot of the asprepared nanoparticles and nanostructures. 

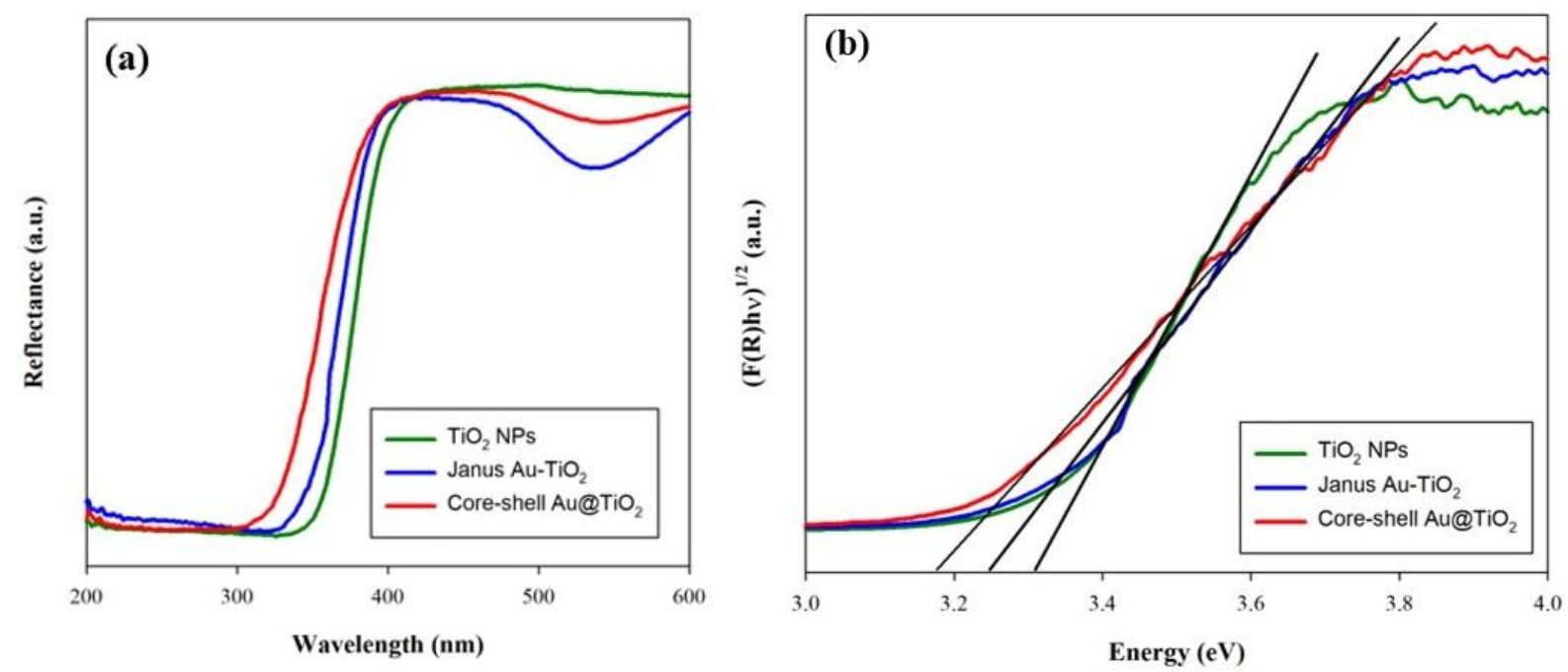

Figure 5 (a) UV-Vis DRS spectra and (b) the corresponding Kubelka-Munk plots of $\mathrm{TiO}_{2}$ nanoparticles, Janus $\mathrm{Au}-\mathrm{TiO}_{2}$ and core-shell $\mathrm{Au} @ \mathrm{TiO}_{2}$ nanostructures

Based on the results, it is clear that heterostructuring could change the light absorption behavior, as well as altering the optical bandgap of the as-prepared anatase $\mathrm{TiO}_{2}$ nanoparticles. Unlike the pristine anatase $\mathrm{TiO}_{2}$ nanoparticles, which only absorb light energy in the range of the UV spectrum, both Janus $\mathrm{Au}-\mathrm{TiO}_{2}$ and core-shell $\mathrm{Au} @ \mathrm{TiO}_{2}$ nanostructures absorb additional light energy in the visible range due to the presence of the plasmonic phenomenon in the $\mathrm{Au}$ nanoparticles (Figure 5a). Furthermore, the estimation of bandgap using the Kubelka-Munk method also reveals that the integration of plasmonic Au nanoparticles could decrease the bandgap of anatase $\mathrm{TiO}_{2}$ ones (Figure 5b). According to the results, the calculated optical bandgap for the Janus $\mathrm{Au}-\mathrm{TiO}_{2}$ and core-shell $\mathrm{Au} @ \mathrm{TiO}_{2}$ nanostructures $(3.25$ and $3.17 \mathrm{eV}$ respectively) were found to be slightly lower than the as-prepared pristine anatase $\mathrm{TiO}_{2}$ nanoparticles $(3.31 \mathrm{eV})$. It is believed that this optical bandgap reduction could be caused by the band shrinkage effect, which occurs due to the deposition of Au nanoparticles (Khan et al., 2013). In addition, such a phenomenon could also be attributed to the presence of the Fermi level as a result of the surface plasmon resonance in the Au nanoparticles.

\section{CONCLUSION}

An investigation of the effect of plasmonic Au nanoparticles in the absorption behavior and optical bandgap of anatase $\mathrm{TiO}_{2}$ nanoparticles has been presented in this work. Well-dispersed anatase $\mathrm{TiO}_{2}$ nanoparticles were successfully synthesized via a sol-gel method and were easily integrated with plasmonic Au nanoparticles to form two types of heterostructure, namely Janus $\mathrm{Au}-\mathrm{TiO}_{2}$ nanostructures and cores-shell Au@ $\mathrm{TiO}_{2}$ nanostructures. Based on the results, the integration of $\mathrm{Au}$ nanoparticles was found to be responsible for the alteration of both light absorption behavior and the optical bandgap of $\mathrm{TiO}_{2}$. The results also show that the two heterostructures were able to absorb not only in the UV range, but also in the visible light spectrum. In addition, Kubelka-Munk estimation also revealed that the optical bandgap of the heterostructures was slightly lower than that of the corresponding pristine anatase $\mathrm{TiO}_{2}$ nanoparticles.

\section{ACKNOWLEDGEMENT}

This work was financially supported by the Indonesian Ministry of Research, Technology and Higher Education (Kemenristekdikti RI) through Hibah Penelitian Dasar Unggulan Perguruan Tinggi (PDUPT) No. 375/UN.R3.1/HKP05.00/2018. 


\section{REFERENCES}

Ahmed, S., Ahmad, M., Swami, B.L., Ikram, S., 2016. A Review on Plants Extract Mediated Synthesis of Silver Nanoparticles for Antimicrobial Applications: A Green Expertise. Journal of Advanced Research, Volume 7(1), pp. 17-28

Ayati, A., Ahmadpour, A., Bamoharram, F.F., Tanhaei, B., Mänttäri, M., Sillanpää, M., 2014. A Review on Catalytic Applications of $\mathrm{Au} / \mathrm{TiO}_{2}$ Nanoparticles in the Removal of Water Pollutant. Chemosphere, Volume 107, pp. 163-174

Chen, X., Burda, C., 2008. The Electronic Origin of the Visible-light Absorption Properties of C-, N-And S-Doped $\mathrm{TiO}_{2}$ Nanomaterials. Journal of the American Chemical Society, Volume 130(15), pp. 5018-5019

Clavero, C., 2014. Plasmon-induced Hot-electron Generation at Nanoparticle/metal-oxide Interfaces for Photovoltaic and Photocatalytic Devices. Nature Photonics, Volume 8(2), pp. 95-103

Dette, C., Pérez-Osorio, M.A., Kley, C.S., Punke, P., Patrick, C.E., Jacobson, P., Giustino, F., Jung, S.J., Kern, K., 2014. $\mathrm{TiO}_{2}$ Anatase with a Bandgap in the Visible Region. Nano Letters, Volume 14(11), pp. 6533-6538

Devi, L.G., Kumar, S.G., Murthy, B.N., Kottam, N., 2009. Influence of Mn2+ and Mo6+ dopants on the Phase Transformations of $\mathrm{TiO}_{2}$ Lattice and Its Photo Catalytic Activity under Solar Illumination. Catalysis Communications, Volume 10(6), pp. 794-798

Duan, H., Wang, D., Li, Y., 2015. Green Chemistry for Nanoparticle Synthesis. Chemical Society Reviews, Volume 44(16), pp. 5778-5792

Haiss, W., Thanh, N.T., Aveyard, J., Fernig, D.G., 2007. Determination of Size and Concentration of Gold Nanoparticles from UV- Vis Spectra. Analytical Chemistry, Volume 79(11), pp. 4215-4221

Hernández-Ramírez, E., Wang, J.A., Chen, L.F., Valenzuela, M.A., Dalai, A.K., 2017. Partial Oxidation of Methanol Catalyzed with $\mathrm{Au} / \mathrm{TiO}{ }_{2}, \mathrm{Au} / \mathrm{ZrO}_{2}$ and $\mathrm{Au} / \mathrm{ZrO}_{2}-\mathrm{TiO}_{2}$ Catalysts. Applied Surface Science, Volume 399, pp. 77-85

Hidalgo, M.C., Aguilar, M., Maicu, M., Navío, J.A., Colón, G., 2007. Hydrothermal Preparation of Highly Photoactive $\mathrm{TiO}_{2}$ Nanoparticles. Catalysis Today, Volume 129(1-2), pp. 50-58

Hidalgo, M.C., Maicu, M., Navío, J.A., Colón, G., 2009. Effect of Sulfate Pretreatment on Goldmodified $\mathrm{TiO}_{2}$ for Photocatalytic Applications. The Journal of Physical Chemistry $C$, Volume 113(29), pp. 12840-12847

Khalil, M., Jan, B.M., Tong, C.W., Berawi, M.A., 2017. Advanced Nanomaterials in Oil and Gas Industry: Design, Application and Challenges. Applied Energy, Volume 191, pp. 287-310

Khan, M.M., Ansari, S.A., Lee, J., Cho, M.H., 2013. Enhanced Optical, Visible Light Catalytic And Electrochemical Properties of $\mathrm{Au} @ \mathrm{TiO}_{2}$ Nanocomposites. Journal of Industrial and Engineering Chemistry, Volume 19(6), pp. 1845-1850

Li, W., Yang, J., Wu, Z., Wang, J., Li, B., Feng, S., Deng, Y., Zhang, F., Zhao, D., 2012. A Versatile Kinetics-Controlled Coating Method to Construct Uniform Porous $\mathrm{TiO}_{2}$ Shells for Multifunctional Core-shell Structures. Journal of the American Chemical Society, Volume 134(29), pp. 11864-11867

Lin, Z., Wang, X., Liu, J., Tian, Z., Dai, L., He, B., Han, C., Wu, Y., Zeng, Z., Hu, Z., 2015. On the Role of Localized Surface Plasmon Resonance in UV-Vis Light Irradiated $\mathrm{Au} / \mathrm{TiO}_{2}$ Photocatalysis Systems: Pros and Cons. Nanoscale, Volume 7(9), pp. 4114-4123

Low, J., Cheng, B., Yu, J., 2017. Surface Modification and Enhanced Photocatalytic $\mathrm{CO}_{2}$ Reduction Performance of $\mathrm{TiO}_{2}$ : A Review. Applied Surface Science, Volume 392, pp. 658686

Medina-Ramírez, I., Liu, J.L., Hernández-Ramírez, A., Romo-Bernal, C., Pedroza-Herrera, G., Jáuregui-Rincón, J., Gracia-Pinilla, M.A., 2014. Synthesis, Characterization, Photocatalytic 
Evaluation, and Toxicity Studies of $\mathrm{TiO}_{2}-\mathrm{Fe} 3+$ Nanocatalyst. Journal of Materials Science, Volume 49(15), pp. 5309-5323

Polte, J., Ahner, T.T., Delissen, F., Sokolov, S., Emmerling, F., Thünemann, A.F., Kraehnert, R., 2010. Mechanism of Gold Nanoparticle Formation in the Classical Citrate Synthesis Method Derived from Coupled in Situ XANES and SAXS Evaluation. Journal of the American Chemical Society, Volume 132(4), pp. 1296-1301

Ran, H., Fan, J., Zhang, X., Mao, J., Shao, G., 2018. Enhanced Performances of Dye-sensitized Solar Cells based on $\mathrm{Au}-\mathrm{TiO}_{2}$ and $\mathrm{Ag}-\mathrm{TiO}_{2}$ Plasmonic Hybrid Nanocomposites. Applied Surface Science, Volume 430, pp. 415-423

Sharma, N., Ojha, H., Bharadwaj, A., Pathak, D.P., Sharma, R.K., 2015. Preparation and Catalytic Applications of Nanomaterials: A Review. RSC Advances, Volume 5(66), pp. 53381-53403

Singaravelan, R., Alwar, S.B.S., 2015. Electrochemical Synthesis, Characterisation and Phytogenic Properties of Silver Nanoparticles. Applied Nanoscience, Volume 5(8), pp. $983-$ 991

Singh, P., Kim, Y.J., Wang, C., Mathiyalagan, R., Yang, D.C., 2016. The Development of a Green Approach for the Biosynthesis of Silver and Gold Nanoparticles by using Panax Ginseng Root Extract, and Their Biological Applications. Artificial cells, Nanomedicine, and Biotechnology, Volume 44(4), pp. 1150-1157

Sofyan, N., Ridhova, A., Yuwono, A.H., Udhiarto, A., 2017. Fabrication of Solar Cells with $\mathrm{TiO}_{2}$ Nanoparticles Sensitized using Natural Dye Extracted from Mangosteen Pericarps. International Journal of Technology, Volume 8(7), pp. 1229-1238

Tahir, M., Amin, N.S., 2015. Indium-doped $\mathrm{TiO}_{2}$ Nanoparticles for Photocatalytic $\mathrm{CO}_{2}$ Reduction with $\mathrm{H}_{2} \mathrm{O}$ Vapors to $\mathrm{CH}_{4}$. Applied Catalysis B: Environmental, Volume 162, pp. 98-109

Tan, Y.N., Wong, C.L., Mohamed, A.R., 2011. An Overview on the Photocatalytic Activity of Nano-doped-TiO ${ }_{2}$ in the Degradation of Organic Pollutants. ISRN Materials Science, 2011.

Tauc, J., 1968. Optical Properties and Electronic Structure of Amorphous Ge and Si. Materials Research Bulletin, Volume 3(1), pp. 37-46

Zhang, J., Jin, X., Morales-Guzman, P.I., Yu, X., Liu, H., Zhang, H., Razzari, L., Claverie, J.P., 2016. Engineering the Absorption and Field Enhancement Properties of $\mathrm{Au}-\mathrm{TiO}_{2}$ Nanohybrids via Whispering Gallery Mode Resonances for Photocatalytic Water Splitting. ACS Nano, Volume 10(4), pp. 4496-4503 